\title{
The Modulation of ENSO Variability in CCSM3 by Extratropical Rossby Waves
}

\author{
SHAYNE MCGREGOR \\ Risk Frontiers, and Department of Physical Geography, Macquarie University, Sydney, New South Wales, Australia \\ Alex Sen Gupta \\ Centre for Climate Change Research, University of New South Wales, Sydney, New South Wales, Australia \\ NeIL J. HOLBROOK \\ School of Geography and Environmental Studies, University of Tasmania, Hobart, Tasmania, Australia \\ SCOTT B. POWER \\ Centre for Australian Weather and Climate Research, Bureau of Meteorology, Melbourne, Victoria, Australia
}

(Manuscript received 10 November 2008, in final form 22 June 2009)

\begin{abstract}
Evidence suggests that the magnitude and frequency of the El Niño-Southern Oscillation (ENSO) changes on interdecadal time scales. This is manifest in a distinct shift in ENSO behavior during the late 1970s. This study investigates mechanisms that may force this interdecadal variability and, in particular, on modulations driven by extratropical Rossby waves. Results from oceanic shallow-water models show that the Rossby wave theory can explain small near-zonal changes in equatorial thermocline depth that can alter the amplitude of simulated ENSO events. However, questions remain over whether the same mechanism operates in more complex coupled general circulation models (CGCMs) and what the magnitude of the resulting change would be. Experiments carried out in a state-of-the-art $z$-coordinate primitive equation model confirm that the Rossby wave mechanism does indeed operate. The effects of these interactions are further investigated using a partial coupling (PC) technique. This allows for the isolation of the role of wind stress-forced oceanic exchanges between the extratropics and the tropics and the subsequent modulation of ENSO variability. It is found that changes in the background state of the equatorial Pacific thermocline depth, induced by a fixed offequatorial wind stress anomaly, can significantly affect the probability of ENSO events occurring. This confirms the results obtained from simpler models and further validates theories that rely on oceanic wave dynamics to generate Pacific Ocean interdecadal variability. This indicates that an improved predictive capability for seasonal-to-interannual ENSO variability could be achieved through a better understanding of extratropical-to-tropical Pacific Ocean transfers and western boundary processes. Furthermore, such an understanding would provide a physical basis to enhance multiyear probabilistic predictions of ENSO indices.
\end{abstract}

\section{Introduction}

El Niño-Southern Oscillation (ENSO) is the dominant mode of interannual variability in the earth climate system affecting climate, river flows, agricultural production, and disease over widespread regions of the world (e.g., Ropelewski and Halpert 1987, 1989; Philander

Corresponding author address: Shayne McGregor, Department of Physical Geography, Macquarie University, Sydney 2109, Australia.

E-mail: shayne.mcgregor@gmail.com
1990). While ENSO variability is dominated by interannual signals, an interdecadal change in the magnitude and frequency of ENSO events and its teleconnections is apparent in both observations and models (e.g., Allan et al. 1996; Power et al. 1999; Fedorov and Philander 2000; Mann et al. 2000; Walland et al. 2000; Arblaster et al. 2002; Vimont et al. 2002; Power et al. 2006; Power and Smith 2007). These changes in ENSO variability are highlighted by the apparent shift in ENSO behavior observed during the late 1970s (e.g., Fedorov and Philander 2000; Power and Smith 2007). After this time, La Niña events became less frequent, El Niño events become 
more frequent, and the two most intense El Niño episodes in more than a century occurred (1982/83 and 1997/98). A major challenge for climate scientists is to accurately predict both the interannual and interdecadal variations in this climate mode.

Over the last few decades, process-based studies with simple and intermediate complexity coupled models have contributed to our theoretical understanding of the oscillatory (e.g., Cane and Zebiak 1985; Zebiak and Cane 1987; Schopf and Suarez 1988; Battisti and Hirst 1989; Jin 1997a,b) and seasonal phase-locking behavior of ENSO (e.g., Tziperman et al. 1997; Neelin et al. 2000). When combined with the vast improvements in modeling of the global climate system, we have been steadily increasing our knowledge and ability to predict future ENSO events. The mechanisms driving interdecadal variability of tropical Pacific sea surface temperature (SST) are less well understood and there is no clear consensus as to the causes of this variability. However, a number of complementary mechanisms have been proposed to account for the natural variability. These are the following: (i) internally generated stochastic atmospheric variability driving interdecadal variability in ENSO (e.g., Kleeman and Power 1994; Kleeman and Moore 1997; Newman et al. 2003; Power and Colman 2006; Power et al. 2006); (ii) nonlinear dynamics of the coupled system affecting the system on interdecadal time scales (e.g., Jin et al. 1994; Tziperman et al. 1994; Timmermann 2003; Rodgers et al. 2004; Schopf and Burgman 2006); and (iii) extratropical variability that remotely drives changes in the tropics on interdecadal time scales. This extratropical variability can be transmitted to the tropical Pacific Ocean via the atmosphere (e.g., Barnett et al. 1999; Pierce et al. 2000), ocean (e.g., Kleeman et al. 1999; Lysne et al. 1997), or a combination of both (Wu et al. 2007). The oceanic induced changes occur via either changes to the shallow meridional overturning circulation (e.g., Kleeman et al. 1999; McPhaden and Zhang 2002; Nonaka et al. 2002), or through extratropical oceanic first baroclinic mode Rossby waves driven by wind stress changes (e.g., Lysne et al. 1997; Liu et al. 1999; Capotondi and Alexander 2001; Capotondi et al. 2003; Wang et al. 2003a,b).

This study focuses on the Rossby wave mechanism. Westward-propagating extratropical Rossby waves driven by wind stress changes impinge on the Pacific Ocean western land boundary where they create coastally trapped waves that propagate equatorward. Upon reaching the equator these coastally trapped waves excite lowfrequency equatorially trapped Kelvin waves that drive changes in the equatorial thermocline depth. It has been suggested that the resulting near-zonal variations in thermocline depth (McGregor et al. 2007) act to modulate
ENSO events by changing the "background" state in which ENSO operates. Numerous investigators have studied the effects of extratropical oceanic Rossby waves on the equatorial Pacific Ocean with models of varying complexity (e.g., Lysne et al. 1997; Liu et al. 1999; Capotondi and Alexander 2001; Hazeleger et al. 2001; Capotondi et al. 2003; Galanti and Tziperman 2003; Luo et al. 2003; Wang et al. 2003a,b; Wu et al. 2003; McGregor et al. 2004; Tourre et al. 2005; McGregor et al. 2007, 2008, 2009). We note that while there is uncertainty regarding the latitudes of importance for the extratropical Rossby wave propagation and the magnitude of the equatorial region response, the overriding message from these studies is that extratropical oceanic Rossby waves do affect the background state of the tropical Pacific Ocean. In simpler models even a relatively small change in the equatorial region background state has been shown to modulate the simulated ENSO behavior (McGregor et al. 2008, 2009). However, the way that the Rossby wave induced changes in the Pacific Ocean background state interact with, and affect, ENSO variability in the complex setting of a coupled GCM (CGCM) has not been studied to date.

This study investigates the role of Rossby waveinduced extratropical-to-tropical Pacific Ocean exchanges on the variability of ENSO magnitude and frequency in the National Center for Atmospheric Research (NCAR) Community Climate System Model, version 3.0 (CCSM3). To begin, we will first show that the mechanisms on which Rossby wave theory relies operate in the ocean component of CCSM3. We then use a partial coupling (PC) approach to constrain ocean-atmosphere coupling to the equatorial region while poleward of this region simulated climatological wind stresses are used to force the model ocean. Similar techniques have been used by Sen Gupta and England (2007) to examine ocean-atmosphere feedbacks associated with Southern Hemisphere extratropical variability in CCSM3 and by Wu et al. (2003) and Solomon et al. (2008) to investigate equatorial region decadal variability. This PC simulation is compared with a free running CCSM3 control simulation (from which the climatological wind stresses used for the PC run are obtained). The difference between these two simulations gives an indication of how prominent the Rossby wave mechanism is in generating ENSO variability. A series of additional experiments are carried out using the PC configuration whereby a fixed wind stress perturbation is added in the subtropical partially coupled region. Of primary interest is the degree to which any wind stress induced extratropical-to-tropical transfers are able to modulate the simulated ENSO variability and whether these interactions can help to explain the differences seen in observed ENSO variability 
before and after the mid-1970s (e.g., Fedorov and Philander 2000).

This paper is organized as follows. Section 2 describes the CCSM3 coupled climate model used in our experiments. In section 3 we show that the mechanisms that the Rossby wave theory relies on do indeed operate in the ocean component of CCSM3. In section 4 we investigate the role of extratropical-to-tropical transfers on the modeled ENSO variability. Finally, the results and the possible implications for predictability are discussed in section 5 .

\section{CCSM}

The coupled general circulation model used in this study is the NCAR CCSM3. CCSM3 is a state-of-the art coupled general circulation model comprising four components (atmosphere, ocean, land, and cryosphere) linked by means of a flux coupler. CCSM3 contains significant revisions over previous releases, including new treatments of cloud processes, aerosol radiative forcing, sea ice dynamics, and a diurnal cycle of penetrating solar radiation in the upper ocean (Collins et al. 2006b). The atmospheric component, the Community Atmosphere Model, version 3 (CAM3), is a global general circulation model with 26 vertical levels and an Eulerian spectral dynamical core with triangular truncation at T42 corresponding to a horizontal resolution of $\sim 2.8^{\circ}$ (Collins et al. 2006a). The ocean component is based upon the Parallel Ocean Program (POP) model version 1.4.3 from the Los Alamos National Laboratory. POP has 40 vertical levels and utilizes a dipolar grid with 320 zonal points and 384 meridional points, giving an average resolution of $1.125^{\circ}$ in the zonal direction and $\sim 0.5^{\circ}$ in the meridional direction with higher resolution near the equator. The land surface model lateral resolution is identical to that of CAM3, while the sea ice model resolution is the same as POP. Detailed descriptions of each of the atmosphere, ocean, land, and cryosphere component models can be found in Collins et al. (2006a), Smith and Gent (2004), Dickinson et al. (2006), and Holland et al. (2006). In the CCSM3 simulations presented here (based on the NCAR b30.004 control run) we used prescribed 1990 level concentrations of greenhouse gases and all aerosol species (sulfate, dust, carbon, sea-salt, and volcanics) along with a fixed solar constant and annually cycling concentrations of ozone.

CCSM3 produces ENSO variability with realistic equatorial SST amplitudes, variance, and zonal extent (Deser et al. 2006). The period of the modeled ENSO, however, is $\sim 2-2.5 \mathrm{yr}$, which is significantly shorter than the observed quasi-periodicity of 2.5-8 yr. Composites of modeled ENSO variability display a seasonal evolution of SST anomalies (SSTAs), which also display realistic maximum amplitudes near the end of the calendar year and phase transitions during the boreal spring. CCSM3 also displays characteristics that are qualitatively similar with the recharge oscillator and delayed action oscillator paradigms for ENSO variability (Deser et al. 2006).

\section{Extratropical-tropical Pacific Ocean pathways}

To begin, an assessment is made of the sensitivity of oceanic Rossby wave propagation to anomalous atmospheric forcing in the extratropics (poleward of $12.5^{\circ}$ latitude) and the associated equatorial responses (between $12.5^{\circ}$ latitude). To this end, the ocean and ice component of CCSM are used with specified atmospheric forcing. This forcing is made up of observed climatological (long-term monthly mean) surface forcing from the (National Centers for Environmental Prediction) NCEP-NCAR reanalyses (Kalnay et al. 1996) during 1985-90. In these simulations POP was initialized from the end of a 500-yr simulation with Coordinated Ocean-Ice Reference Experiment (CORE) forcing (Griffies et al. 2008; this represents a slightly modified NCEP-NCAR forcing) followed by a 120-yr integration with the NCEPNCAR forcing prior to any experimentation or analysis.

Two perturbation experiments were then integrated for $10 \mathrm{yr}$ with this model configuration. In experiment Ia an extratropical Northern Hemisphere-dominated wind stress perturbation was added to the climatological forcing, whereas in experiment $\mathrm{Ib}$ an extratropical Southern Hemisphere-dominated perturbation was added to the climatological forcing. The spatial pattern of these perturbations for each hemisphere was calculated as follows. The first singular value decomposition (SVD) of the cross-covariance matrix of the zonal and meridional components of the monthly NCEP-NCAR reanalysis wind stresses anomalies (long-term monthly mean removed) was calculated between $15^{\circ}$ and $25^{\circ}$ latitude of the given hemisphere over the period 1950-2005; see Bretherton et al. (1992) for more details on the SVD method. Poleward of $25^{\circ}$ latitude, previous studies (e.g., Nonaka et al. 2002; McGregor et al. 2007) have demonstrated negligible remote forcing of tropical variability. We note, however, that the importance of the higherlatitude extratropical ocean for tropical Pacific variability is still debatable because of the model limitations of the aforementioned studies. The normalized principal components corresponding to the first SVD mode are then regressed onto the wind stress anomalies at each grid point over the global domain, making global spatial patterns of the wind stress perturbation. Finally the tropical response is masked out by linearly tapering the wind stress to zero between $15^{\circ}$ and $10^{\circ}$ latitude (Fig. 1). The 

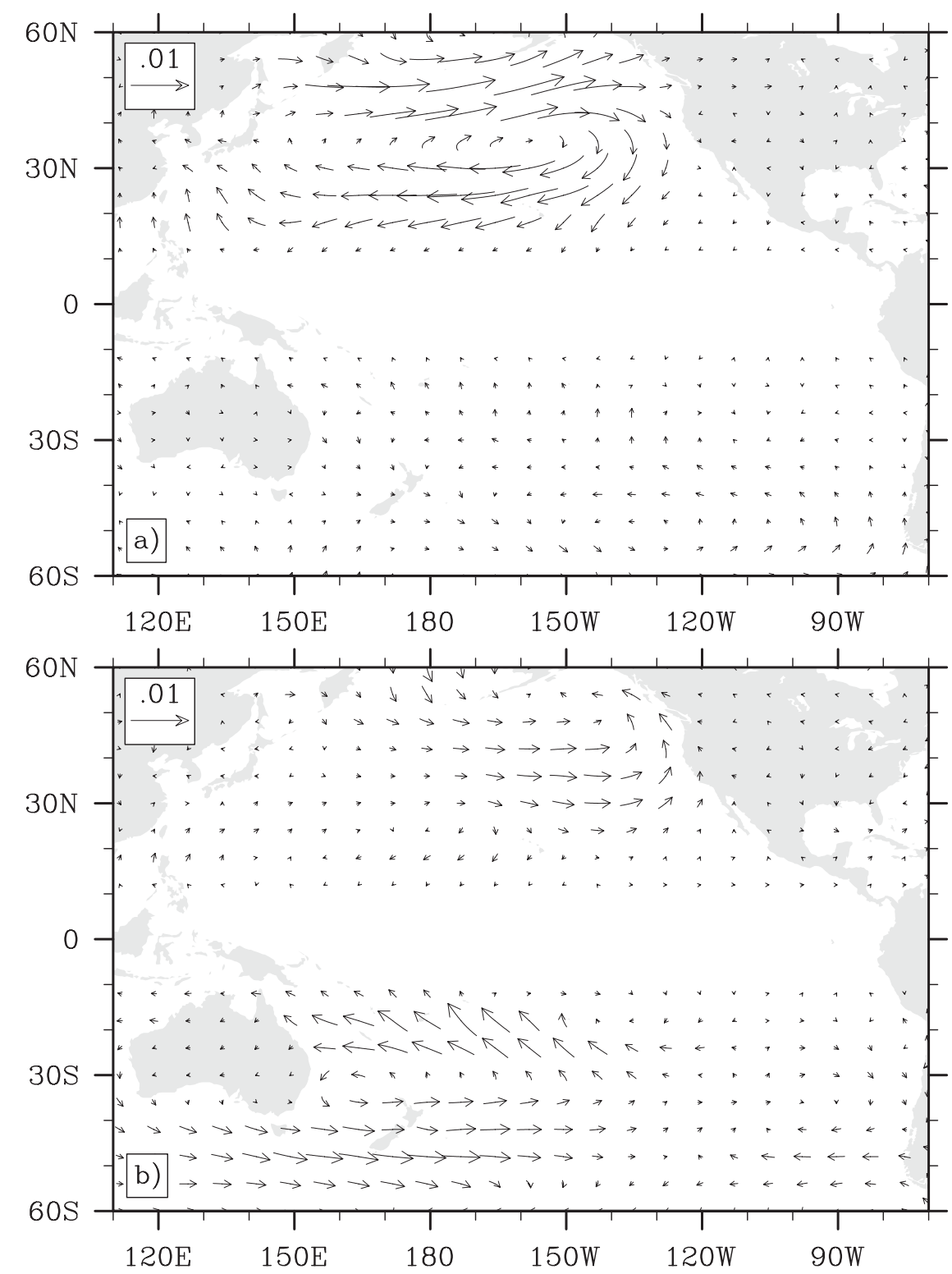

FIG. 1. The wind stresses perturbation $\left(\mathrm{N} \mathrm{m}^{-2}\right.$ ) used for (a) experiment Ia (the first principal component of the $x$ and $y$ components of monthly NCEP-NCAR reanalysis wind stresses anomalies between $15^{\circ}$ and $25^{\circ} \mathrm{N}$ for the period $1950-2005$, regressed onto global wind stress anomalies), and (b) experiment $\mathrm{Ib}$ [defined as in (a), but for the region $15^{\circ}$ and $25^{\circ} \mathrm{S}$ ]. Regression patterns are tapered to 0 in the tropics and between $10^{\circ}$ and $15^{\circ}$ in each hemisphere.

wind stress anomalies were held fixed at two standard deviations for the entire simulation period (i.e., $10 \mathrm{yr}$ ).

While the method for generating the wind stress perturbation was quite arbitrary, these wind stress perturbations and their magnitude are consistent with Pacific Ocean decadal variability wind stress changes identified by previous studies. For example, the Northern Hemispheredominated wind stress perturbation of experiment Ia (see Fig. 1a) is consistent with a change in strength of the Aleutian low and is similar in structure to the observed joint mode of variability between wind stress and SST identified in the study of Kleeman et al. (1999). This joint mode of variability was shown to be involved in the generation of interdecadal variability of an intermediate complexity coupled model (Kleeman et al. 1999; Klinger et al. 2002; Solomon et al. 2003), while a wind stress pattern of similar structure was also shown to be responsible for the generation of decadal variability in the coupled GCM study of Latif and Barnett $(1994,1996)$. Furthermore, the magnitude of the perturbation used 

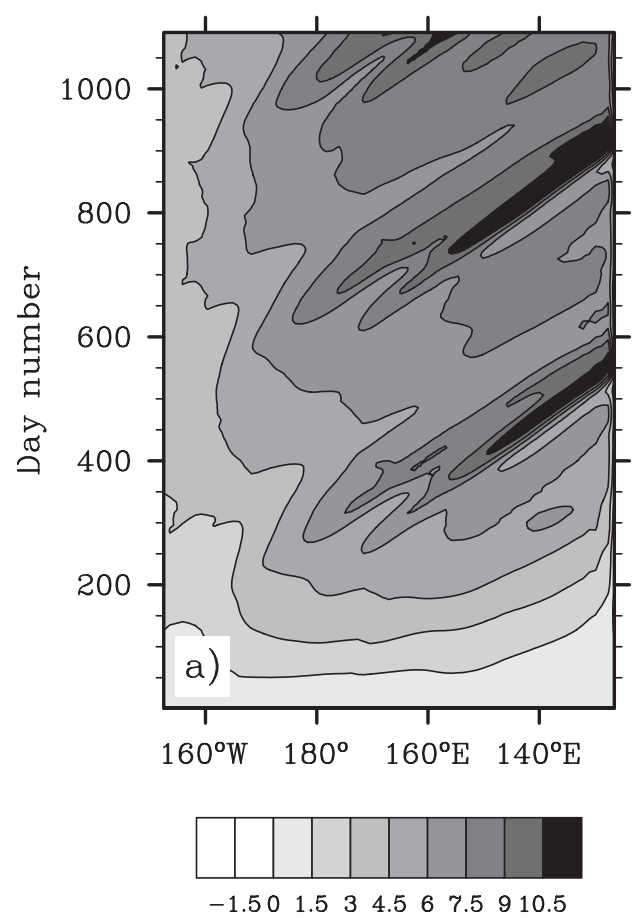
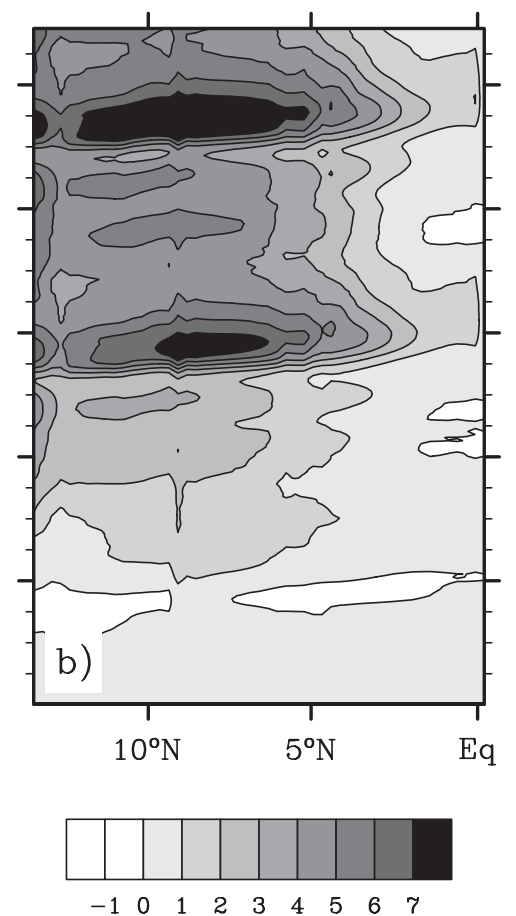
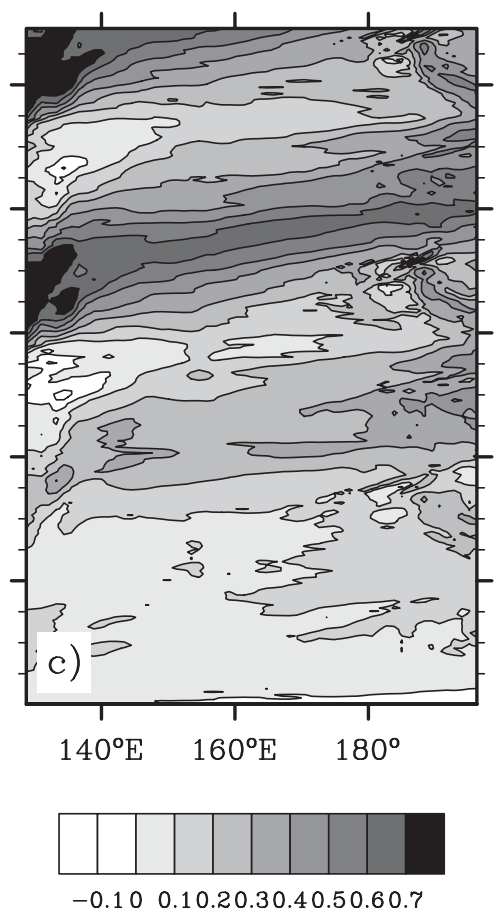

FIG. 2. Anomalies of pycnocline depth (m) from experiment Ia along (a) $14^{\circ} \mathrm{N}$ between $125^{\circ} \mathrm{E}$ and $150^{\circ} \mathrm{W}$ (where values on the $x$ axis are reversed to show westward propagation going from left to right), (b) $\sim 127^{\circ} \mathrm{E}$ (hugging the Philippine coastline between $14^{\circ}$ and $5^{\circ} \mathrm{N}$ ) between $14^{\circ} \mathrm{N}$ and the equator, and (c) the equator.

here is consistent with variations of wind stress generated in an AGCM when forced by the first EOF of SST anomalies in the North Pacific region smoothed with a 3-yr running mean filter (Latif and Barnett 1996, see their Fig. 7a). The wind stress perturbation pattern derived for the Southern Hemisphere used in experiment $\mathrm{Ib}$ (Fig. 1b) is consistent with a northward displacement of the South Pacific convergence zone. It is similar in structure and of a slightly larger magnitude $(\sim 1.3$ times larger) to the changes in surface winds associated with interdecadal ENSO-like variability reported in Garreaud and Battisti (1999, see their Fig. 7).

Using the $1022 \mathrm{~kg} \mathrm{~m}^{-3}$ isopycnal as a proxy for the position of the model pycnocline, the addition of the wind stress perturbation in the Northern Hemisphere in experiment Ia creates a downwelling (upwelling) pycnocline anomaly in the central North Pacific centered around $14^{\circ} \mathrm{N}\left(34^{\circ} \mathrm{N}\right)$. The location of the pycnocline perturbations are consistent with the regions of Ekman-pumping velocity (estimated as $\rho f^{-1}$ times the curl of the wind stress) associated with the wind stress perturbation. Looking at the temporal evolution of the anomaly at $14^{\circ} \mathrm{N}$ in the latitude-time plot (Fig. 2a), it is clear that once generated anomalies begin to propagate westward at speeds $\left(\sim 19 \mathrm{~cm} \mathrm{~s}^{-1}\right)$ consistent with Rossby wave speeds calculated using the geographically varying first baroclinic mode gravity wave speeds of Chelton et al.
(1998). Figure 2a clearly shows a seasonality to the Rossby wave generation that cannot be explained without nonlinear interactions between the generated Rossby wave and the seasonally varying oceanic flow. Upon reaching the western Pacific boundary, which at this latitude is the east coast of the Philippines, this Rossby wave generates a coastally trapped wave (CTW), with an amplitude that is approximately 2 times that expected from linear theory (Kessler 1991), which propagates toward the equator (Fig. 2b). Finally, upon reaching the equator after approximately 1 yr the CTW generates an equatorial Kelvin wave that then propagates eastward across the Pacific basin, lowering the equatorial pycnocline depth (Fig. 2c). The resulting equatorial Kelvin wave has an average maximum amplitude of $\sim 0.6 \mathrm{~m}$, which is much smaller than the original amplitude of the CTW. This is partly due to the fact that the Philippine coast ends $\sim 5^{\circ}$ latitude short of the equator, so some of the CTW energy wraps around the Philippine south coast and begins to propagate northward up the west coast of the Philippines. Thus, it appears that the transfer of energy between the CTW and an equatorial Kelvin wave is not very efficient. Testing the model response with a reversed polarity Northern Hemisphere wind stress perturbation reveals that the modeled wave response is phase linear (i.e., there is an inverted response with a shoaling thermocline signal that propagates along the equator). 

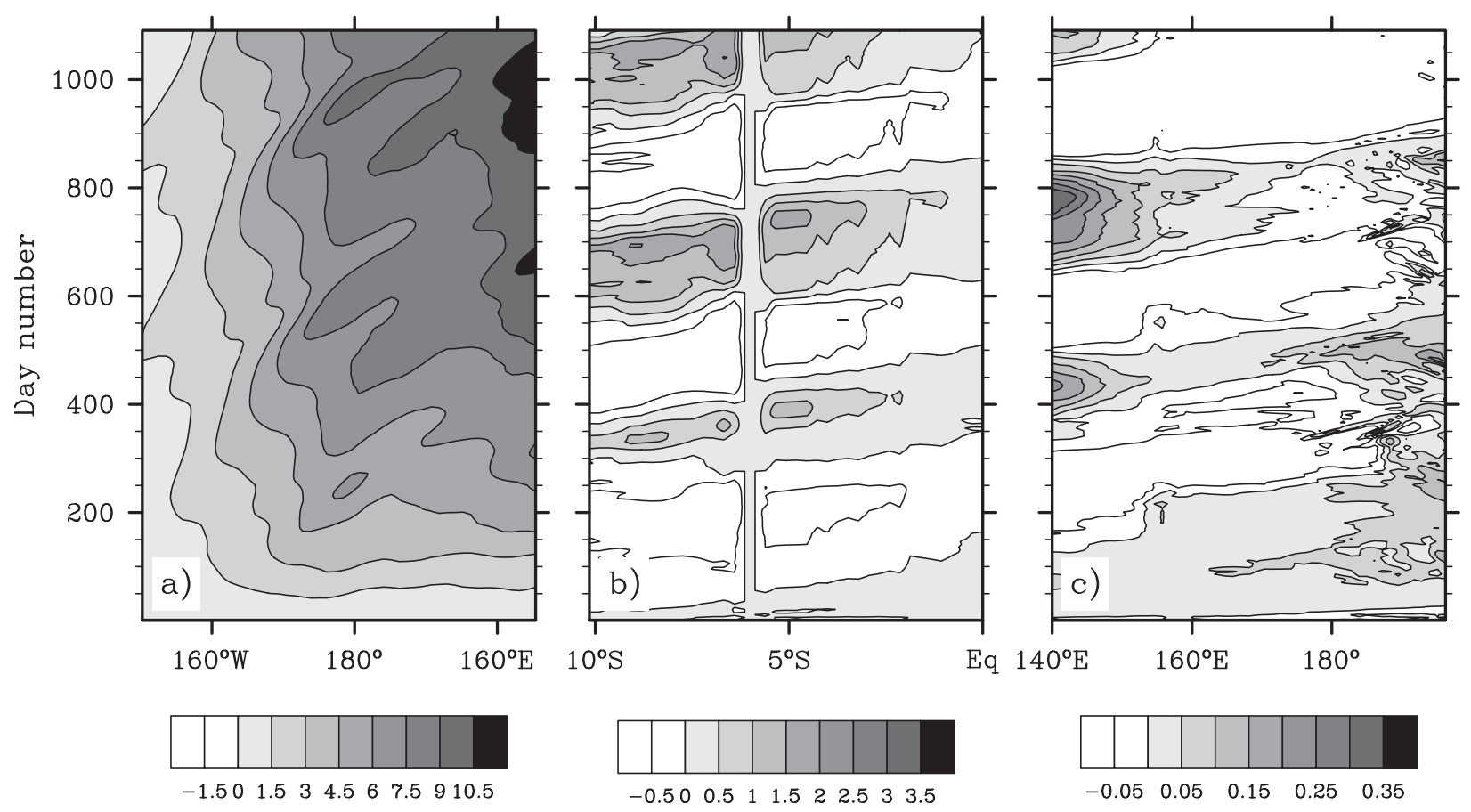

FIG. 3. Anomalies of pycnocline depth (m) from experiment $\mathrm{Ib}$ along (a) $13^{\circ} \mathrm{S}$ between $150^{\circ} \mathrm{E}$ and $170^{\circ} \mathrm{W}$ (where values on the $x$ axis are reversed to show westward propagation going from left to right), (b) the New Guinea coastline between $10^{\circ} \mathrm{S}$ and the equator, and (c) the equator.

The addition of the Southern Hemisphere wind stress perturbation in experiment $\mathrm{Ib}$ (Fig. 1b) creates a downwelling (upwelling) pycnocline anomaly in the westerncentral South Pacific centered around $13^{\circ} \mathrm{S}\left(27^{\circ} \mathrm{S}\right)$. The locations of these pycnocline perturbations are again consistent with the regions of Ekman pumping associated with the wind stress perturbation. Once generated, the pycnocline anomalies at $13^{\circ} \mathrm{S}$ (Fig. 3a) begin to propagate westward at a similar speed to their Northern Hemisphere counterpart $\left(\sim 17 \mathrm{~cm} \mathrm{~s}^{-1}\right)$. Again, there appears to be some nonlinear interaction between the oceanic monthly mean flow and the propagating waves as the Rossby wave amplitude waxes and wanes with season. Upon reaching the western Pacific boundary, Australia and New Guinea in this case, the Rossby wave generates a CTW that propagates toward the equator (Fig. 3b) with an amplitude that is consistent with linear theory (Kessler 1991). After approximately $1.5 \mathrm{yr}$ when the CTW reaches the equator, an equatorial Kelvin wave is generated that then propagates across the Pacific basin lowering the equatorial pycnocline depth (Fig. 3c). Interestingly, even with the coastline of New Guinea providing a land boundary all the way to the equator the amplitude of the CTW decreases dramatically as the equator is approached. The area of the largest decline in wave amplitude appears to be where the coastline of New Guinea becomes particularly complex (between $\sim 5^{\circ} \mathrm{S}$ and the equator).
These experiments show that simple Rossby wave theory goes a long way to explaining the propagation features of these waves in more complex, $z$-coordinate, CGCM models. Consistent with experiments in simpler models (e.g., McGregor et al. 2009), the actual equatorial pycnocline anomaly is much smaller than the original signal in the central Pacific Ocean. Nevertheless, the Rossby wave propagation and wave magnitudes are clear down to a depth of $\sim 300 \mathrm{~m}$ in the tropical Pacific Ocean. As such this analysis is relatively insensitive to the choice of isopycnal used as a proxy for the pycnocline depth.

\section{CCSM3 partial coupling experiments}

A PC technique similar to that described by Wu et al. (2003) was used in our CCSM3 experiments to help isolate the role of wind stress-forced oceanic exchanges between the extratropics and the tropics in modulating simulated ENSO variability. In the PC configuration, the ocean model sees a prescribed annual cycle of surface wind stress in a specified region (the PC region) and sees the prognostic wind stresses from the full oceanatmosphere coupling elsewhere. In these experiments full ocean-atmosphere coupling is confined to the equatorial region (between $12.5^{\circ} \mathrm{S}$ and $12.5^{\circ} \mathrm{N}$; anomalies from the long-term monthly mean are linearly tapered 

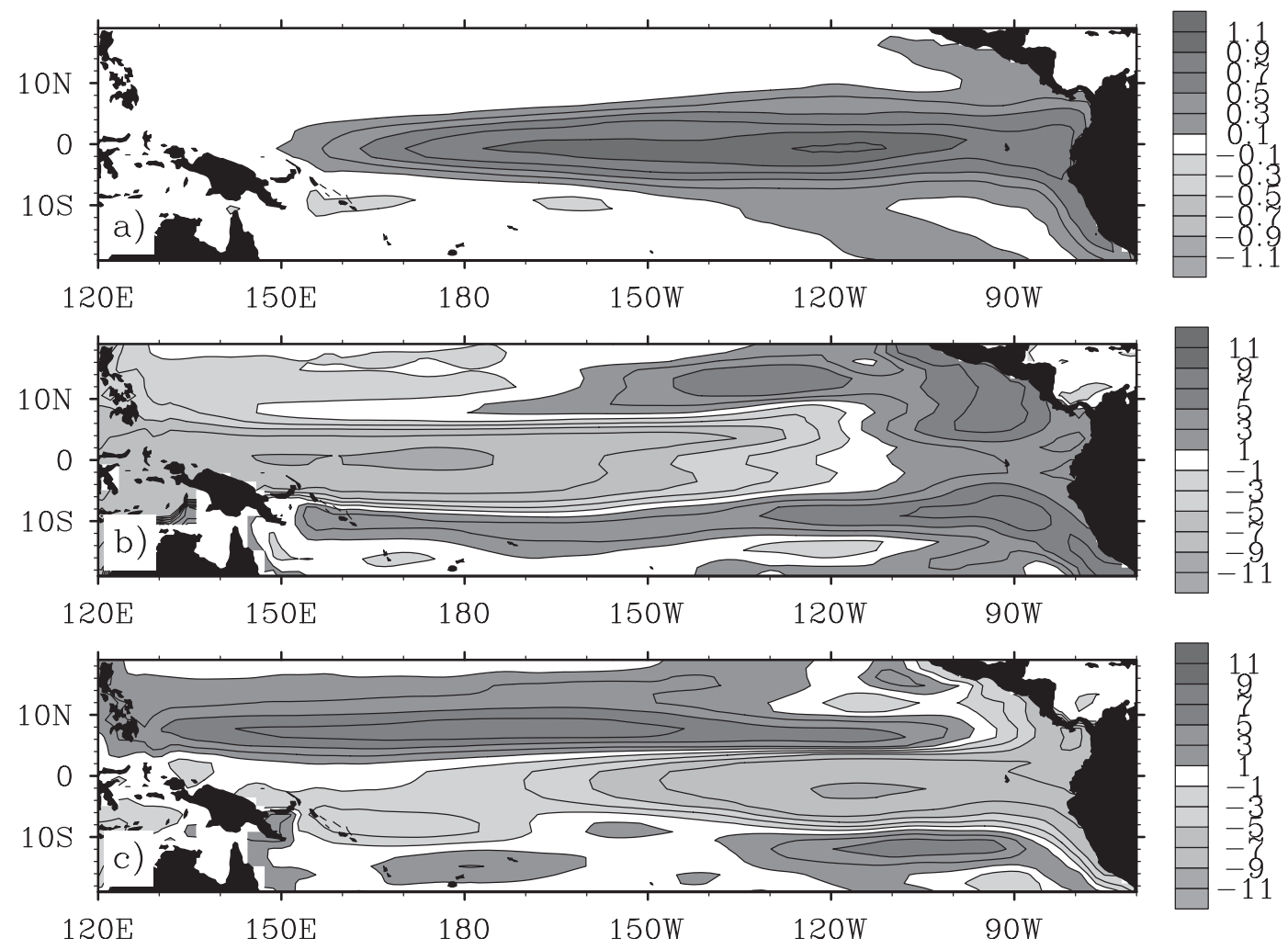

FIG. 4. The first EOFs of the PC CCSM3 simulation for (a) SST anomalies in ${ }^{\circ} \mathrm{C}$ (explaining $33.5 \%$ variance), (b) pycnocline depth anomalies in $\mathrm{m}$ (explaining $20.5 \%$ variance), and shown in (c) the second EOF of the PC CCSM3 simulation pycnocline depth in $\mathrm{m}$ (explaining $17 \%$ variance).

to 0 between $10^{\circ}$ and $15^{\circ}$ latitude) while poleward of this region we use the PC approach, where only long-term monthly mean wind stresses from a 400-yr control simulation are applied. Other surface fluxes (e.g., heat) remain fully interactive and the atmospheric model sees the prognostic SST over the full domain. Therefore, the resulting model configuration effectively only isolates the role of wind stress-forced oceanic exchanges between the extratropics and the tropics. Furthermore, it is unlikely that the atmospheric stochastic variability will be underestimated as has been shown to occur when the PC strategy is reversed (i.e., when a fixed SST boundary condition is used to force the atmospheric model in the PC regions; Barsugli and Battisti 1998). Prior to experimentation the model was run with $\mathrm{PC}$ conditions poleward of $12.5^{\circ}$ latitude for $40 \mathrm{yr}$ to allow for any adjustment and to check for any significant climate drift. No drift was evident.

\section{a. Partial coupling simulation}

To obtain a statistically robust response the PC experiments consisted of 10 ensemble members, each of $10 \mathrm{yr}$. As a first step in the analysis of the modeled data we carry out an EOF analysis on SSTAs and pycnocline depth (estimated by the $1025 \mathrm{~kg} \mathrm{~m}^{-3}$ isopycnal surface generated in the simulations between $30^{\circ} \mathrm{S}-30^{\circ} \mathrm{N}$ and $120^{\circ} \mathrm{E}-70^{\circ} \mathrm{W}$; Fig. 4). The first EOF of SSTA from the 10 simulations combined (which accounts for $33.5 \%$ of the SSTA anomaly variance) is dominated by a tonguelike signal in the central-eastern equatorial Pacific that clearly represents ENSO-like variability (Fig. 4a). The corresponding principal component time series displays interannual variations very similar to the fully coupled CCSM3 1990 (NCEP-NCAR simulation b30.004) control simulation with its high-frequency bias (cf. observations; Fig. 5a).

The first EOF of pycnocline depth shown in Fig. 4b (accounting for $\sim 21 \%$ of the pycnocline anomaly variance) displays an out-of-phase relationship between the eastern and western tropical Pacific consistent with the delayed action oscillator ENSO mechanism (Suarez and Schopf 1988; Battisti and Hirst 1989) and the tilting mode of the recharge-discharge oscillator paradigm (Jin 1997a,b). This is supported by the temporal correlation coefficient of 0.7 between the corresponding principal component and the principal component of the first SSTA EOF (significant above the $99 \%$ confidence level, Fig. 5a). The statistical significance of all correlation 

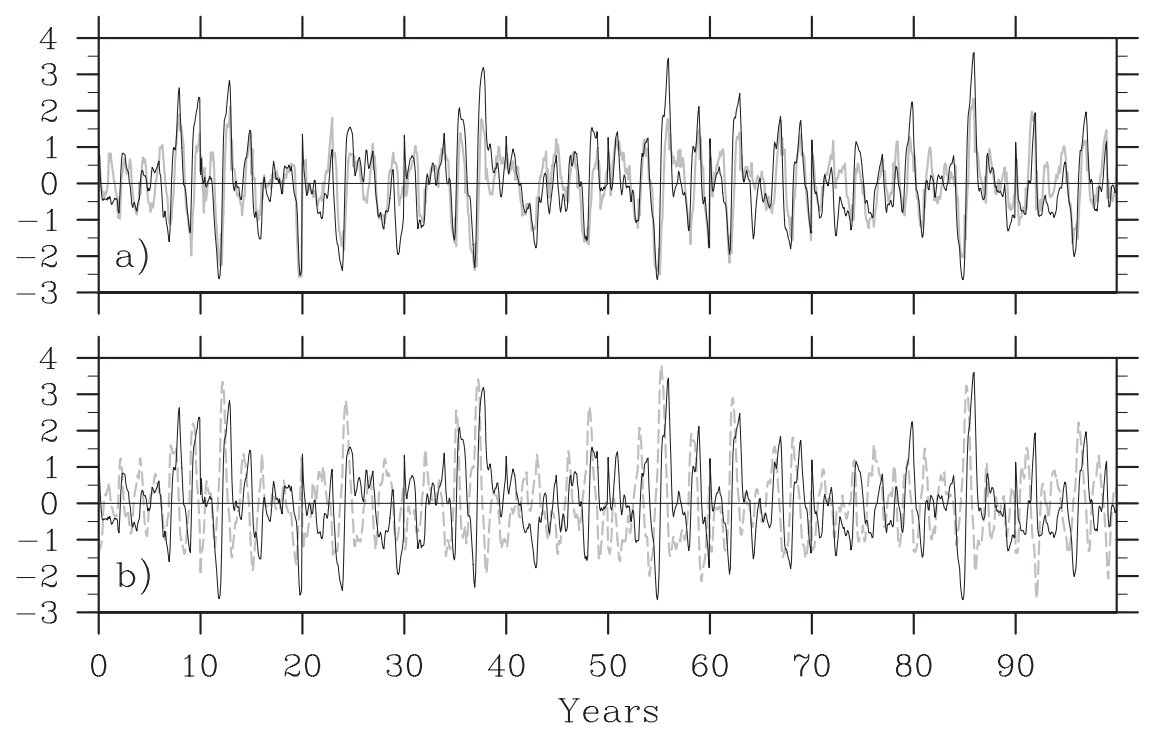

FIG. 5. (a) The principal component time series associated with the first EOF for the PC CCSM3 simulation of SST (gray line) and pycnocline depth (gray line). (b) The principal component time series associated with the first and second EOFs of the PC CCSM3 simulation pycnocline depth are displayed in black and gray respectively.

coefficients determined in this study take account of serial (auto)correlation in the series based on the reduced effective number of degrees of freedom outlined by Davis (1976). The second EOF of the pycnocline depth (which accounts for $16 \%$ of the total pycnocline depth variance) reveals an almost zonally uniform equatorial Pacific weighting similar to the recharge mode (Jin 1997a,b; Fig. 4c). In further support of the recharge paradigm, the associated principal component is strongly correlated (0.62, significant above the $99 \%$ level) with the principal component of the second EOF of pycnocline depth, whereby the former leads the latter by 6 months (Fig. 5b). Thus, as expected the model produces ENSO variability consistent with both the recharge-discharge oscillator and the delay action oscillator without any wind stress-forced exchanges between the off-equatorial and equatorial ocean.

Comparison of the ENSO variability statistics generated in the PC model with those from the fully coupled CCSM3 control simulation indicate that there are no statistically significant changes of the Niño-3, Niño-3.4, or Niño-4 region variance or skewness. Monte Carlo simulations were used to determine the statistical significance of changes in the variance and skewness in the interannual variability (e.g., von Storch and Zweirs 1999). Serial autocorrelation in the SSTA was essentially removed by using annual averages for the June-May period. This analysis shows that by removing wind stress-forced exchanges between the off-equatorial and equatorial $\mathrm{Pa}$ cific Ocean there is little change to the simulated ENSO variability. This could be an indication that these exchanges have little role to play in modulating the ENSO variability in CCSM3. However, Solomon and Zhang (2006) have shown that decadal variability of extraequatorial winds is underestimated in CCSM3. As such, the lack of any significant change may simply indicate that extratropical-to-tropical Pacific Ocean exchanges are underestimated in the control simulation because of the lack of decadal forcing, so the resulting change in ENSO variability is also likely to be underestimated.

\section{b. Experiment IIa}

In experiment IIa we again carry out 10 sets of 10 -yr simulations in the PC configuration. This time, however, the off-equatorial region wind stress pattern, defined in section 3 (cf. Fig. 1a), was added to the climatological forcing in the PC region. In this way we examine whether idealized off-equatorial to equatorial ocean exchanges can modulate the simulated ENSO behavior. The previous experiments show that the addition of this patch of Northern Hemisphere-dominated surface wind stress effectively lowers the equatorial region pycnocline depth by $\sim 0.6 \mathrm{~m}$ during certain seasons, via Rossby and Kelvin wave adjustment. As expected from linear theory and previous experiments using simpler models (e.g., Kessler 1991; McGregor et al. 2009) the equatorial region perturbation is much smaller than the original anomaly associated with the generated Rossby wave. However, according to results from these simple models, even a modest lowering of the equatorial region 


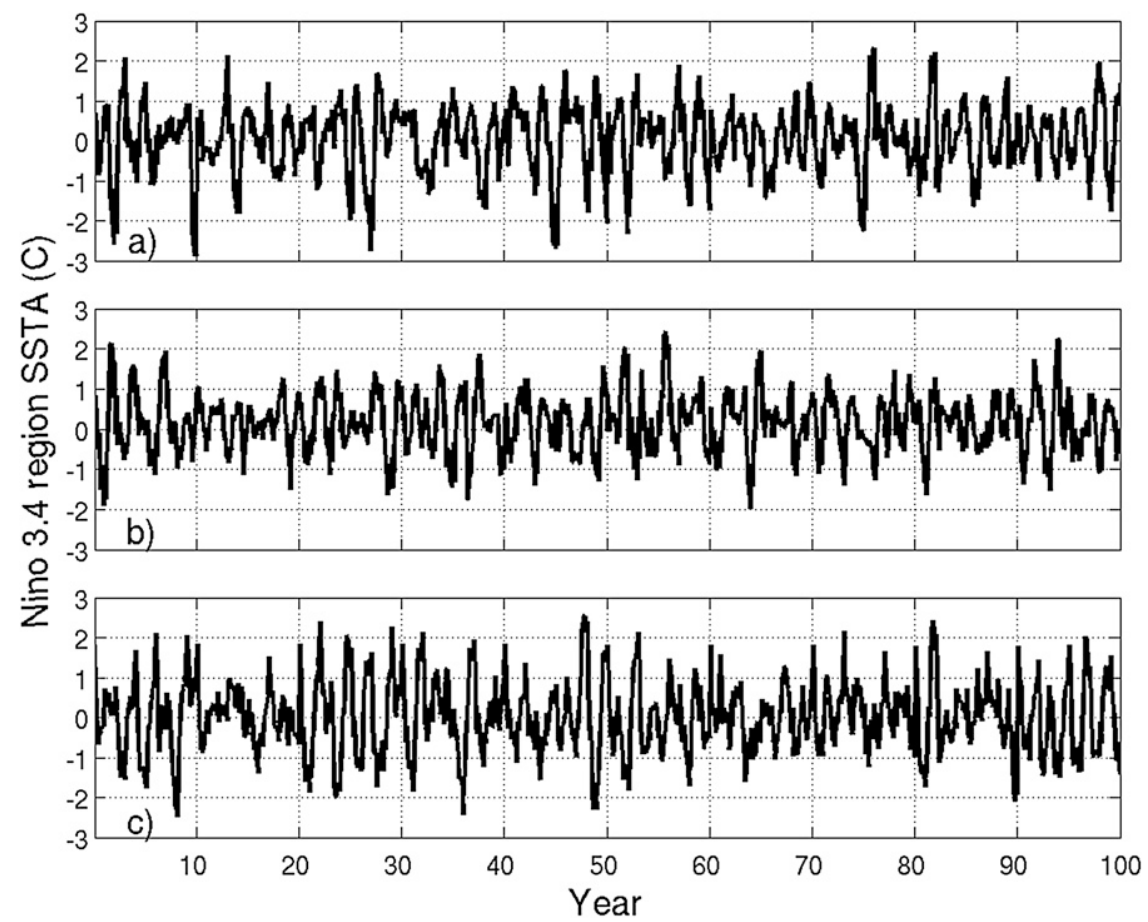

FIG. 6. Niño-3.4 region SSTA for the 10 by 10 -yr CCSM3 simulations, shown consecutively from (a) the PC simulation with no perturbation, (b) experiment IIa, and (c) experiment IIb.

background state pycnocline depth can lead to larger El Niño events, smaller La Niña events, and lower-frequency ENSO variability (e.g., Fedorov and Philander 2000; McGregor et al. 2008, 2009). So does the simulated ENSO variability change as a result of the lower background pycnocline depth?

Looking at either the plots of Niño-3.4 region SSTA (Fig. 6), the statistics of SSTA in the Niño-3, Niño-3.4, and Niño-4 regions (Table 1), or the probability density function (PDF) of the Niño-3.4 SSTA (Fig. 7a) it is clear that there has been a change in the behavior of the modeled ENSO. The lower equatorial region background state has led to a reduced variance that is statistically significant in all three Niño regions at greater than the 95\% confidence level. Furthermore, there is a shift toward more positive skewness that is statistically significant above the $90 \%$ confidence level in both the Niño-3.4 and Niño-4 regions. These changes in ENSO statistics do not appear to change the probability of large El Niño years (large El Niño years are classified here as years between June-May that have a 3-month mean SSTA $>1.5^{\circ} \mathrm{C}$ ) or shift the dominant power spectrum frequency

TABLE 1. The variance and skewness of the Niño-3 (N3), Niño-3.4 (N34), and Niño-4 (N4) region SSTA where statistically significant differences greater than the $95 \%(90 \%)$ levels between the PC simulation and the PC experiments are in bold (italics).

\begin{tabular}{|c|c|c|c|c|c|}
\hline & \multirow[b]{2}{*}{ Region } & \multicolumn{2}{|c|}{ Monthly } & \multicolumn{2}{|c|}{ Annual } \\
\hline & & Variance & Skewness & Variance & Skewness \\
\hline b30.004 control & N3 & 0.704 & -0.101 & 0.475 & -0.116 \\
\hline \multirow[t]{2}{*}{ (Year 700-800) } & N34 & 0.786 & -0.219 & 0.480 & -0.403 \\
\hline & N4 & 0.540 & -0.299 & 0.278 & -0.656 \\
\hline \multirow[t]{3}{*}{ PC simulation } & N3 & 0.694 & -0.192 & 0.510 & -0.228 \\
\hline & N34 & 0.713 & -0.466 & 0.427 & -0.618 \\
\hline & N4 & 0.481 & -0.547 & 0.230 & -1.039 \\
\hline \multirow[t]{3}{*}{ PC Expt. IIa } & N3 & 0.505 & 0.076 & 0.327 & 0.036 \\
\hline & N34 & 0.514 & 0.129 & 0.275 & -0.059 \\
\hline & N4 & 0.362 & -0.137 & 0.139 & -0.445 \\
\hline \multirow{3}{*}{ PC Expt. IIb } & N3 & 0.674 & 0.252 & 0.427 & 0.195 \\
\hline & N34 & 0.748 & 0.193 & 0.405 & -0.142 \\
\hline & $\mathrm{N} 4$ & 0.521 & -0.067 & 0.251 & -0.554 \\
\hline
\end{tabular}



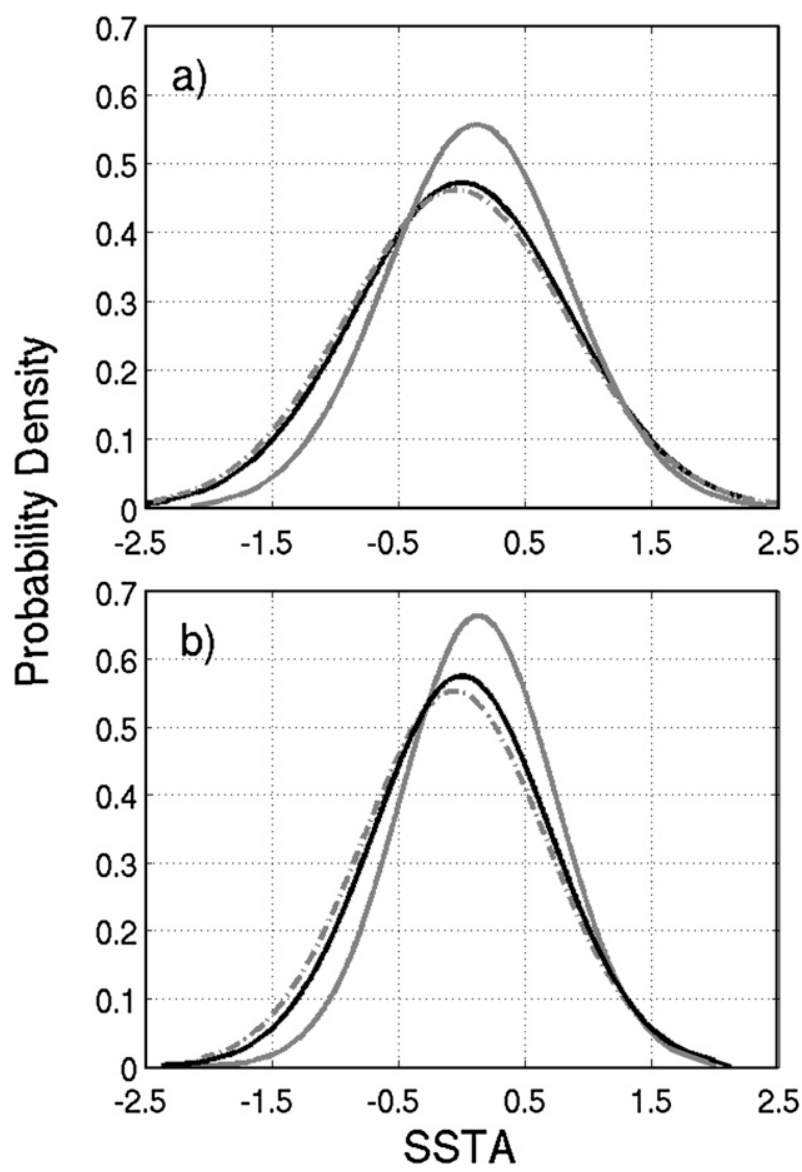

FIG. 7. PDFs of the (a) Niño-3.4 and (b) Niño-4 region SSTA for the unperturbed PC simulation (solid black line), experiment IIa (solid gray line), and experiment IIb (dashed-dotted gray line).

(Fig. 8), but are manifest as a significant reduction in the power spectrum at ENSO frequencies and the probability of large La Niña years. For example, for strong La Niña years (large La Niña years are classified here as years between June and May that have a 3-month mean SSTA $<-1.5^{\circ} \mathrm{C}$ ) the probability in a given year of reaching this threshold is reduced from $\sim 7.7 \%$ to $\sim 2.2 \%$ with the offequatorially induced lowering of the equatorial pycnocline (Table 2). Furthermore, this shift in ENSO variability also manifests itself as a statistically significant warming in equatorial region SSTA, located in the western to central equatorial Pacific (Fig. 9). While small in magnitude the change in mean SST is statistically significant above the $95 \%$ level. This change in mean temperature is also approximately 5 (7) times larger than the equivalent Niño-3.4 (Niño-4) region mean SST response obtained in experiment Ia, where the same forcing was applied in the forced ocean-ice model.

Given that the added wind perturbation of this experiment can generate extratropical SSTA that can interact with the overlying atmosphere; we need to confirm

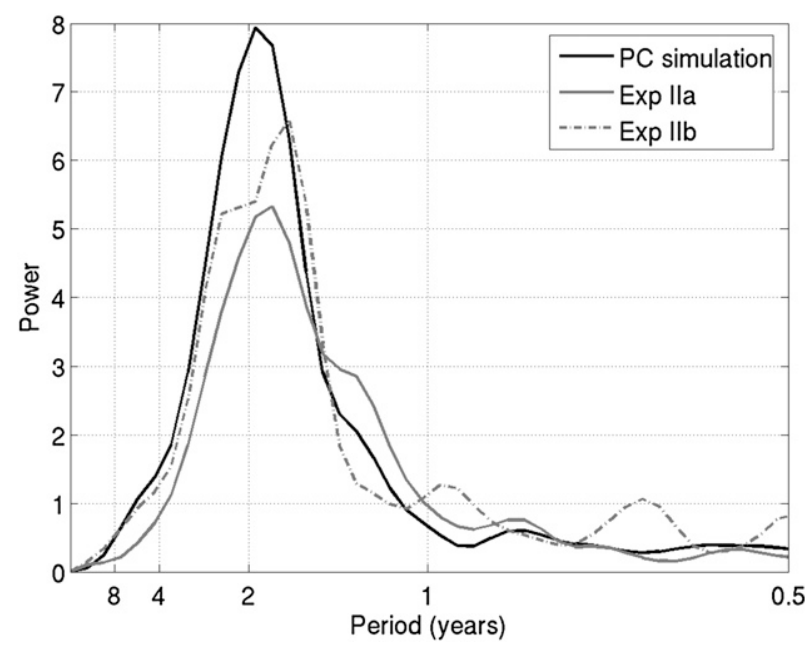

FIG. 8. The mean power spectra of Niño-3.4 region SST for the 10 by 10 -yr CCSM3 simulations of the unperturbed PC simulation (solid black line), experiment IIa (solid gray line), and experiment IIb (dashed-dotted gray line).

that atmospheric teleconnections do not have a role to play in this shift in ENSO variability. To this end, we carried out a further experiment consisting of a series of ten 10-yr PC CCSM3 simulations. In each of these simulations the PC model had an added SSTA perturbation in the extratropical Pacific. This SSTA perturbation was calculated as the mean anomalies of SST generated during experiment Ia (not shown). The small equatorial region anomalies were masked out as they are not directly related to the wind stress perturbation; instead they rely on ocean dynamic processes. If the model response was being forced through the atmosphere of CCSM3 by the anomalous SST pattern generated, we would expect the ENSO variability of this PC simulation to reflect those seen during the original PC experiment, experiment IIa. However, this is not the case. This experiment produces no statistically significant change in ENSO statistics. As such, the extratropical ocean-induced changes in the equatorial region must be responsible for the shift in ENSO behavior seen in this manuscript.

\section{c. Experiment IIb}

In experiment IIb a similar set of ensemble runs are conducted, except this time the Northern Hemisphere-

TABLE 2. The probability of 3-month running means of Niño-3.4 region SSTA exceeding the given temperature thresholds in any given year (June-May).

\begin{tabular}{lcccccr}
\hline \hline & $<-1.5$ & $<-1.0$ & $<-0.5$ & $>0.5$ & $>1.0$ & $>1.5$ \\
\hline PC simulation & $7.7 \%$ & $21.9 \%$ & $38.5 \%$ & $53.8 \%$ & $26.4 \%$ & $9.9 \%$ \\
PC Expt. IIa & $2.2 \%$ & $13.2 \%$ & $31.8 \%$ & $53.8 \%$ & $27.4 \%$ & $8.8 \%$ \\
PC Expt. IIb & $8.8 \%$ & $27.5 \%$ & $50.5 \%$ & $41.8 \%$ & $25.3 \%$ & $12.1 \%$ \\
\hline
\end{tabular}




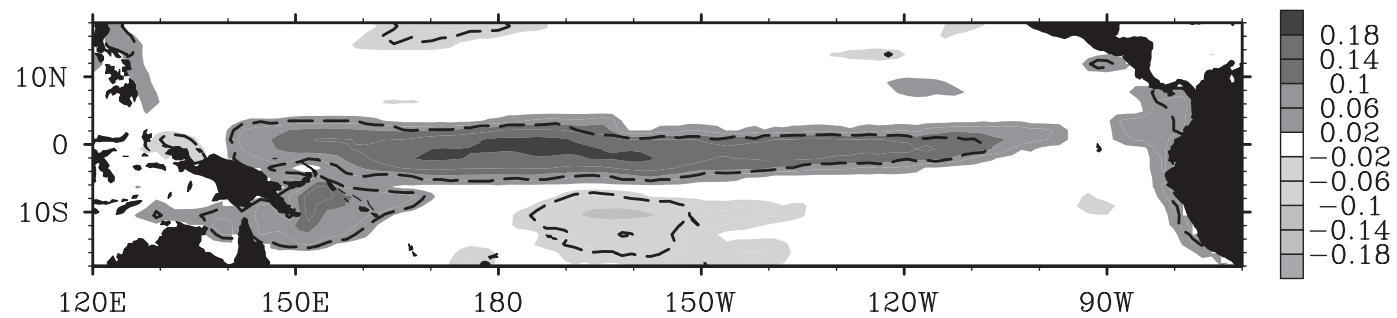

FIG. 9. The change in the mean state SST $\left({ }^{\circ} \mathrm{C}\right)$ due to the addition of the off-equatorial wind stress forcing in experiment IIa. Only SST changes that are statistically significant above the $90 \%$ level shaded. The dashed black line indicates statistically significant changes above the $95 \%$ level.

dominated perturbation is applied with reversed polarity (i.e., we now have a cyclonic anomaly in the extratropical North Pacific). In contrast to the positive perturbation, this surface wind stress pattern effectively raises the equatorial region pycnocline depth by $\sim 0.6 \mathrm{~m}$ via Rossby and Kelvin wave adjustment. Once again, results from previous simpler models indicate that even a modest raising of the equatorial region background state pycnocline depth can lead to larger La Niña events and smaller El Niño events (Fedorov and Philander 2000; McGregor et al. 2008, 2009).

Visual inspection of the Niño-3.4 region SSTA (Fig. 6) or comparison of the Niño-3, Niño-3.4, and Niño-4 region SSTA statistics (Table 1) reveals that there is no statistically significant change in frequency, mean state, or variance of ENSO. However, there is an increase in the skewness of the Niño-4 region SSTA that is statistically significant above the $90 \%$ level. Looking at the PDF of the Niño-4 region SSTA shown in Fig. 7b, this change in skewness corresponds to the slight shift toward the left in the main body of the distribution. This slight change in ENSO statistics essentially increases the chances of cool SSTA in the equatorial Pacific. For example, if you take a La Niña threshold of $-0.5^{\circ} \mathrm{C}$ (again using the 3-month running mean) in the Niño-3.4 region the probability of getting SSTA cooler than that level is $\sim 38 \%$ in the unperturbed PC CCSM3. In this experiment however, the probability of a SSTA getting cooler than $-0.5^{\circ} \mathrm{C}$ has increased to $\sim 50 \%$ (Table 2 ).

\section{Discussion and conclusions}

A number of complementary mechanisms have been proposed to help explain the interdecadal variability of tropical Pacific SST and ENSO (see the introduction). Particular attention has been given to trying to understand the shift in ENSO behavior seen since the late 1970s. However, there is no clear consensus on the relative importance of the various mechanisms in the observed variability. In this manuscript we focus on identifying the importance of extratropical Rossby waves as a contributing mechanism for such changes in ENSO behavior. We are primarily interested in how large the impacts of wind stress-forced extratropical-to-tropical Pacific Ocean transfers are and whether they act to modulate the modeled ENSO variability.

To investigate whether the Rossby-Kelvin wave mechanism operates in CCSM3, we started out by using the ocean-sea ice components of the model with prescribed atmospheric forcing. Two experiments were carried out in which a spatially varying but temporally constant perturbation was added to the wind stress forcing in the extratropical Northern and Southern Hemisphere region (experiments $\mathrm{Ia}$ and $\mathrm{Ib}$ ). We show that the mechanisms that the Rossby wave theory relies on (oceanic Rossby waves and coastal and equatorial Kelvin waves) operate in the more complicated ( $z$ coordinate) CCSM3. Consistent with the work of Solomon et al. (2008), the generated signal takes $\sim 1$ yr to get to the equatorial region. However, in contrast to more idealized models, the CTW loses a large proportion of its magnitude while propagating along the western continental boundary. This appears to result from the lack of a continental connection between the offequatorial region and the equator (in experiment Ia) or propagation along a highly complex coastline (e.g., the New Guinea continental boundary in experiment Ib). The realism with regard to the reduction in CTW amplitude is an intriguing question, which will hopefully be addressed by some of the observational work being carried out as part of the South Pacific Ocean Circulation and Climate Experiment (SPICE; Ganachaud et al. 2007).

A model surgery approach called partial coupling (PC) was employed next to isolate the role of wind stress-forced oceanic exchanges between the extratropics and the tropics on the modeled ENSO variability. This PC approach allowed us to constrain ocean-atmosphere coupling to the equatorial region with prescribed climatological wind stresses poleward of these regions, effectively removing wind stress-forced exchanges between the off-equatorial and equatorial Pacific Ocean. A comparison of ENSO statistics from the PC experiment and the fully coupled CCSM3 control simulation 
showed no statistically significant changes to the Niño-3, Niño-3.4, or Niño-4 region variance or skewness. While this could be an indication that exchanges between the off-equatorial and equatorial Pacific Ocean play only a minor role in modulating ENSO variability, it may also indicate that extratropical-to-tropical Pacific Ocean exchanges are underestimated in the model (Solomon and Zhang 2006).

To further test this, two perturbation experiments were conducted within the PC configuration. In these experiments we added a fixed magnitude Northern Hemisphere subtropical wind stress perturbation to the off-equatorial region of the PC CCSM3 model. We know from our initial set of experiments that these perturbations change the background state of the equatorial region. While idealized, this experimental approach gives us the best opportunity to identify what could potentially be a small signal in the large variability present in the equatorial region. The perturbation used in both experiments (IIa and IIb) has the same structure as that used in the oceanonly experiment Ia (Fig. 1a), except in experiment IIb the sign of the pattern is reversed.

In experiment IIa the change in background state (deeper equatorial pycnocline) significantly reduces the number of La Niña years but produces no significant change to the number of El Niño years (Fig. 7; Table 2). La Niña (El Niño) years are defined as years that have a 3-month running mean Niño-3 region SSTA of less (more) than $-0.5^{\circ} \mathrm{C}\left(+0.5^{\circ} \mathrm{C}\right)$. Years are defined from June to May. However, this background state change produces no significant change in the power spectrum of ENSO variability consistent with the work of Solomon et al. (2003) or the number of El Niño years (El Niño years are defined here as years between June and May that have a 3-month mean SSTA $>0.5^{\circ} \mathrm{C}$; see Fig. 7 and Table 2). This nonlinearity with respect to the sign of ENSO can be understood by analyzing the changes in average equatorial Pacific temperature anomalies (between $2^{\circ} \mathrm{S}$ and $2^{\circ} \mathrm{N}$ ) in the presence of the off-equatorial wind stress perturbation. The main changes in temperature occur well below the surface within the thermocline (Fig. 10). During a weak La Niña event anomalous upwelling of thermocline water occurs, which is now $\sim 0.1^{\circ} \mathrm{C}$ warmer than normal. The anomalous upwelling rate is calculated by forcing the ocean component of CCSM3 with a fixed equatorial wind stress (where the equatorial wind stress is calculated as the first SVD mode of the zonal and meridional components of NCEP-NCAR reanalysis winds between $15^{\circ} \mathrm{S}$ and $15^{\circ} \mathrm{N}$ ) to obtain a Niño-3.4 region SSTA of $\sim-0.5^{\circ} \mathrm{C}$. This upwelling acts to effectively couple the thermocline temperature changes with the surface, thereby increasing the eastern equatorial Pacific SSTA relative to a weak La Niña event without a lowered background state equatorial pycnocline depth. This acts to suppress the associated atmospheric positive feedback, which reduces the chance of upwelling water from below the thermocline and hence, getting large La Niña events. On the other hand, during an El Niño event, equatorial upwelling is reduced helping to keep the thermocline anomaly decoupled from the surface.

In experiment $\mathrm{IIb}$, there is little significant change to the power spectrum of ENSO events, which is consistent with the work of Solomon et al. (2003), or the number of simulated extreme ENSO events (Fig. 7). However, there is a shift toward more negative values in the main body of the frequency distribution, implying an increased probability of small magnitude La Niña events occurring and a corresponding decrease in small magnitude El Niño events (see Fig. $7 b$ and Table 2). This shift is again consistent with changes to the average equatorial temperature anomalies (between $2^{\circ} \mathrm{S}$ and $2^{\circ} \mathrm{N}$ ) resulting from the off-equatorial wind stress perturbation. The main change in temperature is a cooling that occurs at the thermocline level, which is almost a mirror image of the warming shown in Fig. 10. As discussed above, during a small La Niña event anomalous upwelling of subsurface water occurs and water from within the thermocline, which is now $\sim 0.1^{\circ} \mathrm{C}$ cooler, is raised to the surface. The reduced SSTA, relative to a La Niña event of similar magnitude without a background state shoaling thermocline depth, acts to enhance the atmospheric positive feedback increasing the probability of getting larger La Niñas. However, as the anomalous upwelling associated large La Niña events draws water from below the thermocline to the surface and since there is little change in temperature in water below the thermocline it is not surprising that the amplitude of large La Niña events does not increase (Fig. 10).

Can the Rossby wave mechanism be used to help explain the interdecadal shift in ENSO statistics seen since the late 1970s? Experiments by McGregor et al. (2009) forced a linear ocean shallow-water model in the off-equatorial region with NCEP-NCAR reanalysis wind for the period 1950-2006. They found that the late 1970s shift in ENSO statistics corresponded with a deepening of the equatorial region "background" state thermocline depth of $\sim 0.5 \mathrm{~m}$. When this result is combined with the results presented here in experiment IIa, an increase in pycnocline depth of approx $0.5 \mathrm{~m}$ would result in a shift toward a warmer tropical Pacific and a significant decrease in the amplitude of La Niña events. For example, this is equivalent to having the ENSO variability presented in Fig. 6a prior to the late 1970s and the ENSO variability of Fig. 6b since that period. Thus, the combined result is consistent with observed changes (e.g., Fedorov and Philander 2000). 


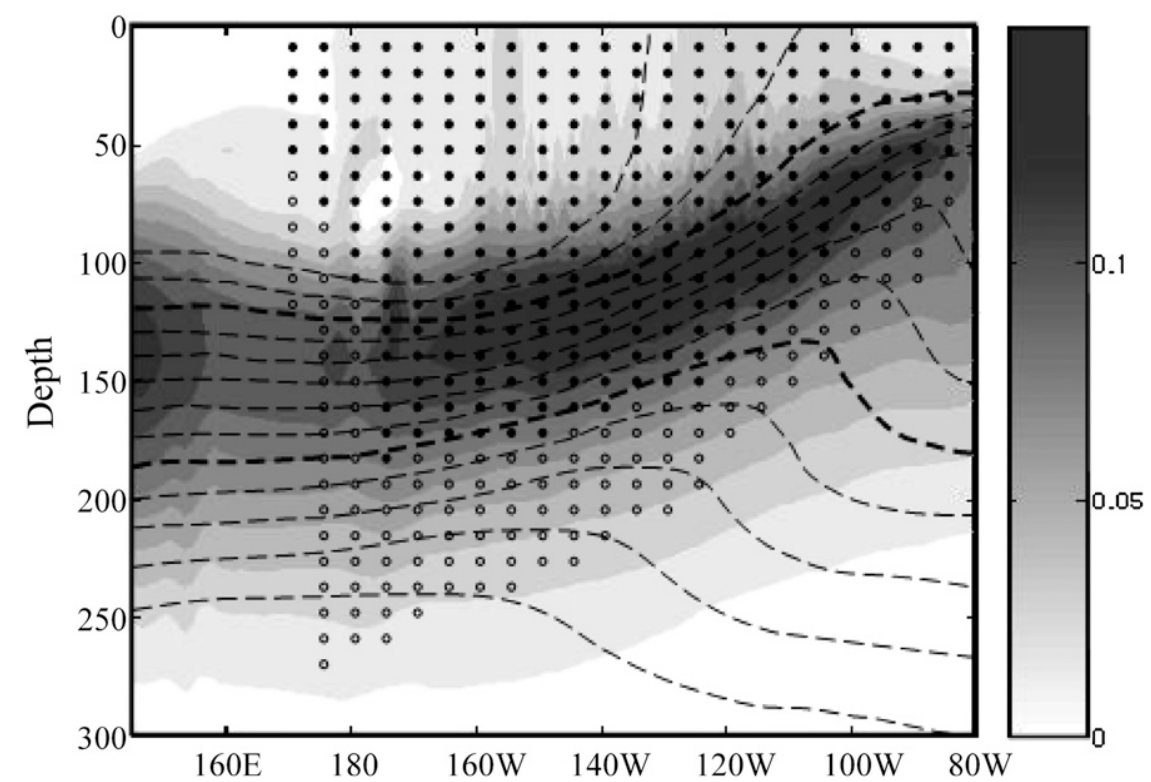

FIG. 10. The mean equatorial region temperature anomaly for experiment Ia with contours of mean temperature between $26^{\circ}$ (at the surface) and $14^{\circ} \mathrm{C}$ (spaced every ${ }^{\circ} \mathrm{C}$ ) overlaid as thin solid back lines. Regions where mean anomalies of upwelling $>0.5 \times 10^{-3} \mathrm{~cm} \mathrm{~s}^{-1}$ during a small La Niña event $\left(\sim-0.5^{\circ} \mathrm{C}\right.$ temperature anomaly in the Niño 3.4 region) are marked by solid stippling, while regions with mean anomalies of upwelling $>0.5 \times 10^{-3} \mathrm{~cm} \mathrm{~s}^{-1}$ during a large La Niña events $\left(\sim-1.5^{\circ} \mathrm{C}\right.$ temperature anomaly in the Niño-3.4 region) are marked with both hollow and solid stippling.

These results also suggest that there is a potential to provide enhanced long-term probabilistic forecasts of ENSO variability based on tracking the initiation and propagation of extratropical Rossby waves. Currently, forecasts of ENSO variability are very sensitive to how individual weather events are represented-the accurate forecasting of single weather events can be the difference between a good and bad ENSO forecast. As such, accurate long lead, deterministic forecasts of ENSO event timing and magnitude appear to be a long way off. Here instead we propose a method that utilizes Bayesian probabilities to enhance long-term ENSO forecasts by using potential predictability of the slowly adjusting offequatorial ocean in much the same way as McGregor et al. (2009) discussed. Consider, for example the likelihood of an ENSO event occurring one year ahead (a time where we have essentially no real deterministic skill): for this task we would use the PDF of the Niño-3.4 region (for this example we use the PC simulation statistics), which suggests a $\sim 90 \%$ chance that the SSTA will fall between $-1.5^{\circ}$ and $1.2^{\circ} \mathrm{C}$. In practical terms, this implies an El Niño or La Niña event exceeding these thresholds is equally likely. However, by using the slowly adjusting dynamics of the off-equatorial ocean to predict the background state of the equatorial Pacific Ocean we can reduce the spread of the probabilistic forecasts of ENSO.
This last step is carried out by selecting the PDF distribution that best represents the range of SSTA that can be expected given the predicted equatorial Pacific background state. If, for example, an increase in thermocline depth background state was predicted, then we would choose the PDF of experiment IIa, which is skewed toward positive SSTA and has a significantly reduced probability of a large La Niña event occurring. Table 2 lists the probabilities for an El Niño or La Niña event conditional upon both of the possible equatorial Pacific Ocean background states. We note that this conceptual idea to enhance multiyear ENSO forecasts is reliant upon the results presented being confirmed with further experimentation in a variety of CGCMs with a range of different background state changes and the availability of accurate forecasts of extratropically induced changes in the equatorial region background state ocean.

This study demonstrates that changes in the background state of the equatorial Pacific Ocean pycnocline depth induced by an idealized off-equatorial wind stress perturbation has a modest but statistically significant effect on the amplitude of the modeled ENSO events. This confirms results obtained from simpler models and further validates the theory suggesting that oceanic wave dynamics can explain at least part of the observed Pacific Ocean interdecadal ENSO variability. As such, 
we believe that a comprehensive understanding and more accurate seasonal-to-interannual prediction of ENSO variability could be achieved by a better understanding of extratropical-to-tropical Pacific Ocean transfers and the related western boundary processes.

Acknowledgments. We wish to thank Caroline Ummenhofer for providing the spun-up CCSM3 ocean component model. S. McGregor's participation was supported by a Macquarie University Research Area Centre's of Excellence (RAACE) Scholarship, Risk Frontiers, and travel support was provided by the Australian Research Council Network for Earth System Science (ARCNESS). S. Power's contribution was supported by the Australian Climate Change Science Program. We would also like to acknowledge the staff and resources at the Australian Partnership for Advanced Computing (APAC) facility for the very valuable computer time allocations that facilitated this study.

\section{REFERENCES}

Allan, R. J., J. Lindesay, and D. E. Parker, 1996: El Niño, Southern Oscillation, and Climatic Variability. CSIRO Publishing, $402 \mathrm{pp}$.

Arblaster, J., G. Meehl, and A. Moore, 2002: Interdecadal modulation of Australian rainfall. Climate Dyn., 18, 519-531.

Barnett, T. P., D. W. Pierce, M. Latif, D. Dommenget, and R. Saravanan, 1999: Interdecadal interactions between the tropics and midlatitudes in the Pacific basin. Geophys. Res. Lett., 26, 615-618.

Barsugli, J. J., and D. S. Battisti, 1998: The basic effects of atmosphereocean thermal coupling on midlatitude variability. J. Atmos. Sci., 55, 477-493.

Battisti, D. S., and A. C. Hirst, 1989: Interannual variability in a tropical atmosphere-ocean model: Influence of the basic state, ocean geometry, and nonlinearity. J. Atmos. Sci., 46, $1687-1712$.

Bretherton, C. S., C. Smith, and J. M. Wallace, 1992: An intercomparison of methods for finding coupled patterns in climate data. J. Climate, 5, 541-560.

Cane, M. A., and S. E. Zebiak, 1985: A theory for El Niño and the Southern Oscillation. Science, 228, 1085-1087.

Capotondi, A., and M. A. Alexander, 2001: Rossby waves in the tropical North Pacific and their role in decadal thermocline variability. J. Phys. Oceanogr., 31, 3496-3515.

,-- , and C. Deser, 2003: Why are there Rossby wave maxima in the Pacific at $10^{\circ} \mathrm{S}$ and $13^{\circ} \mathrm{N}$ ? J. Phys. Oceanogr., 33, 1549-1563.

Chelton, D. B., R. A. deSzoeke, M. G. Schlax, K. El Naggar, and N. Siwertz, 1998: Geographical variability of the first baroclinic Rossby radius of deformation. J. Phys. Oceanogr., 28, 433-460.

Collins, W. D., and Coauthors, 2006a: The formulation and atmospheric simulation of the Community Atmosphere Model: CAM3. J. Climate, 19, 2144-2161.

— , and Coauthors, 2006b: The Community Climate System Model, version 3. J. Climate, 19, 2122-2143.
Davis, R. E., 1976: Predictability of sea surface temperature and sea level pressure anomalies over the North Pacific Ocean. J. Phys. Oceanogr., 6, 249-266.

Deser, C., A. Capotondi, R. Saravanan, and A. S. Phillips, 2006: Tropical Pacific and Atlantic climate variability in CCSM3. J. Climate, 19, 2451-2481.

Dickinson, R. E., K. W. Oleson, G. Bonan, F. Hoffman, P. Thornton, M. Vertenstein, Z. L. Yang, and X. Zeng, 2006: The Community Land Model and its climate statistics as a component of the Community Climate System Model. J. Climate, 19, 2302-2324.

Fedorov, A. V., and S. G. Philander, 2000: Is El Niño changing? Science, 288, 1997-2002.

Galanti, E., and E. Tziperman, 2003: A midlatitude-ENSO teleconnection mechanism via baroclinically unstable long Rossby waves. J. Phys. Oceanogr., 33, 1877-1888.

Ganachaud, A., and Coauthors, 2007: Southwest Pacific Ocean Circulation and Climate Experiment (SPICE). Part I: Scientific background. NOAA/OAR Special Rep./International CLIVAR Project Office CLIVAR Publication Series 111, 1-37.

Garreaud, R. D., and D. S. Battisti, 1999: Interannual (ENSO) and interdecadal (ENSO-like) variability in the Southern Hemisphere tropospheric circulation. J. Climate, 12, 2113-2123.

Griffies, S. M., and Coauthors, 2008: Coordinated Ocean-Ice Reference Experiments (COREs). Ocean Modell., 6, 1-46.

Hazeleger, W., M. Visbeck, M. Cane, A. Karspeck, and N. Naik, 2001: Decadal upper ocean temperature variability in the tropical Pacific. J. Geophys. Res., 106, 8971-8988.

Holland, M. M., C. M. Bitz, E. C. Hunke, W. H. Lipscomb, and J. L. Schramm, 2006: Influence of the sea ice thickness distribution on polar climate in CCSM3. J. Climate, 19, 2398-2414.

Jin, F. F., 1997a: An equatorial ocean recharge paradigm for ENSO. Part I: Conceptual model. J. Atmos. Sci., 54, 811-829. , 1997b: An equatorial ocean recharge paradigm for ENSO. Part II: A stripped-down coupled model. J. Atmos. Sci., 54, 830-847.

_ case: Annual subharmonic steps to chaos. Science, 264, 70-72.

Kalnay, E., and Coauthors, 1996: The NCEP/NCAR 40-Year Reanalysis Project. Bull. Amer. Meteor. Soc., 77, 437-471.

Kessler, W. S., 1991: Can reflected extraequatorial Rossby waves drive ENSO? J. Phys. Oceanogr., 21, 444-452.

Kleeman, R., and S. B. Power, 1994: Limits to predictability in a coupled ocean-atmosphere model due to atmospheric noise. Tellus, 46A, 529-540.

_ and A. M. Moore, 1997: A theory for the limitation of ENSO predictability due to stochastic atmospheric transients. $J$. Atmos. Sci., 54, 753-767.

_ _ J. P. McCreary, and B. A. Klinger, 1999: A mechanism for generating ENSO decadal variability. Geophys. Res. Lett., 26, 1743-1746.

Klinger, B. A., J. P. McCreary Jr., and R. Kleeman, 2002: The relationship between oscillating subtropical wind stress and equatorial temperature. J. Phys. Oceanogr., 32, 1507-1521.

Latif, M., and T. P. Barnett, 1994: Causes of decadal climate variability over the North Pacific and North America. Science, 266, 634-637.

— , and $—$ 1996: Decadal climate variability over the North Pacific and North America: Dynamics and predictability. J. Climate, 9, 2407-2423.

Liu, Z., L. Wu, and E. Bayler, 1999: Rossby wave-coastal Kelvin wave interaction in the extratropics. Part I: Low-frequency adjustment in a closed basin. J. Phys. Oceanogr., 29, 2382-2404. 
Luo, J. J., S. Masson, S. Behera, P. Delecluse, S. Gualdi, A. Navarra, and T. Yamagata, 2003: South Pacific origin of the decadal ENSO-like variation as simulated by a coupled GCM. Geophys. Res. Lett., 30, 2250, doi:10.1029/2003GL018649.

Lysne, J., P. Chang, and B. Giese, 1997: Impact of the extratropical Pacific on equatorial variability. Geophys. Res. Lett., 24, 25892592.

Mann, M. E., R. S. Bradley, and M. K. Hughes, 2000: Long-term variability in the El Niño-Southern Oscillation and associated teleconnections. El Niño and the Southern Oscillation: Multiscale Variability and Global and Regional Impacts, H. F. Diaz and V. Markgraf, Eds., Cambridge University Press, 357-412.

McGregor, S., N. J. Holbrook, and S. B. Power, 2004: On the dynamics of interdecadal thermocline depth and sea surface temperature variability in the low to mid-latitude Pacific Ocean. Geophys. Res. Lett., 31, L24201, doi:10.1029/2004GL021241.

,$- \ldots$, and $—, 2007$ : Interdecadal sea surface temperature variability in the equatorial Pacific Ocean. Part I: The role of off-equatorial wind stresses and oceanic Rossby waves. $J$. Climate, 20, 2643-2658.

,-- , and,- 2008 : Interdecadal sea surface temperature variability in the equatorial Pacific Ocean. Part II: The role of equatorial/off-equatorial wind stresses in a hybrid coupled model. J. Climate, 21, 4242-4256.

,$- \ldots$, and — 2009: The response of a stochastically forced ENSO model to observed off-equatorial wind-stress forcing. J. Climate, 22, 2512-2525.

McPhaden, M. J., and D. Zhang, 2002: Slowdown of the meridional overturning circulation in the upper Pacific Ocean. Nature, 415, 603-608.

Neelin, J. D., F. F. Jin, and H. H. Syu, 2000: Variations in ENSO phase locking. J. Climate, 13, 2570-2590.

Newman, M., G. P. Compo, and M. A. Alexander, 2003: ENSOforced variability of the Pacific decadal oscillation. J. Climate, 16, 3853-3857.

Nonaka, M., S. P. Xie, and J. P. McCreary, 2002: Decadal variations in the subtropical cells and equatorial Pacific SST. Geophys. Res. Lett., 29, 1116, doi:10.1029/2001GL013717.

Philander, S. G., 1990: El Niño, La Niña and the Southern Oscillation. International Geophysics Series, Vol. 46, Academic Press, 293 pp.

Pierce, D. W., T. P. Barnett, and M. Latif, 2000: Connections between the Pacific Ocean tropics and midlatitudes on decadal timescales. J. Climate, 13, 1173-1194.

Power, S., and R. Colman, 2006: Multi-year predictability in a coupled general circulation model. Climate Dyn., 26, 247-272.

— and apparent dominance of El Niño both reach record levels, but has ENSO really changed? Geophys. Res. Lett., 34, L18702, doi:10.1029/2007GL030854.

_ - T. Casey, C. Folland, A. Colman, and V. Mehta, 1999: Interdecadal modulation of the impact of ENSO on Australia. Climate Dyn., 15, 319-324.

—- M. Haylock, R. Colman, and X. Wang, 2006: The predictability of interdecadal changes in ENSO activity and ENSO teleconnections. J. Climate, 19, 4755-4771.

Rodgers, K. B., P. Friederichs, and M. Latif, 2004: Tropical Pacific decadal variability and its relation to decadal modulations of ENSO. J. Climate, 17, 3761-3774.
Ropelewski, C. F., and M. S. Halpert, 1987: Global and regional scale precipitation patterns associated with the El Niño/ Southern Oscillation. Mon. Wea. Rev., 115, 1606-1626.

— and - 1989: Precipitation patterns associated with the high index phase of the Southern Oscillation. J. Climate, 2, 268-284.

Schopf, P. S., and M. J. Suarez, 1988: Vacillations in a coupled ocean-atmosphere model. J. Atmos. Sci., 45, 549-566. , and R. J. Burgman, 2006: A simple mechanism for ENSO residuals and asymmetry. J. Climate, 19, 3167-3179.

Sen Gupta, A., and M. H. England, 2007: Coupled ocean-atmosphere feedback in the southern annular mode. J. Climate, 20, 36773692.

Smith, R. D., and P. R. Gent, 2004: Reference manual for the Parallel Ocean Program (POP), ocean component of the Community Climate Model (CCSM2. 0 and 3.0). 76 pp.

Solomon, A., and D. Zhang, 2006: Pacific subtropical cell variability in coupled climate model simulations of the late 19th20th century. Ocean Modell., 15, 236-249.

, J. P. McCreary Jr., R. Kleeman, and B. A. Klinger, 2003: Interannual and decadal variability in an intermediate coupled model of the Pacific region. J. Climate, 16, 383-405.

_, S. Shin, M. Alexander, and J. McCreary, 2008: The relative importance of tropical variability forced from the North Pacific through ocean pathways. Climate Dyn., 31, 315-331.

Suarez, M. J., and P. S. Schopf, 1988: A delayed action oscillator for ENSO. J. Atmos. Sci., 45, 3283-3287.

Timmermann, A., 2003: Decadal ENSO amplitude modulations: A nonlinear paradigm. Global Planet. Change, 37, 135-156.

Tourre, Y. M., C. Cibot, L. Terray, W. B. White, and B. Dewitte, 2005: Quasi-decadal and inter-decadal climate fluctuations in the Pacific Ocean from a CGCM. Geophys. Res. Lett., 32, L07710, doi:10.1029/2004GL022087.

Tziperman, E., L. Stone, M. A. Cane, and H. Jarosh, 1994: El Niño chaos: Overlapping of resonances between the seasonal cycle and the Pacific Ocean-atmosphere oscillator. Science, 264, 72-74.

, S. E. Zebiak, and M. A. Cane, 1997: Mechanisms of seasonalENSO interaction. J. Atmos. Sci., 54, 61-71.

Vimont, D. J., D. S. Battisti, and A. C. Hirst, 2002: Pacific interannual and interdecadal equatorial variability in a $1000-\mathrm{yr}$ simulation of the CSIRO coupled general circulation model. J. Climate, 15, 160-178.

von Storch, H., and F. W. Zweirs, 1999: Statistical Analysis in Climate Research. Cambridge University Press, 484 pp.

Walland, D. J., S. B. Power, and A. C. Hirst, 2000: Decadal climate variability simulated in a coupled general circulation model. Climate Dyn., 16, 201-211.

Wang, X., F. F. Jin, and Y. Wang, 2003a: A tropical ocean recharge mechanism for climate variability. Part I: Equatorial heat content changes induced by the off-equatorial wind. $J$. Climate, 16, 3585-3598.

,,- , and $-2003 \mathrm{~b}$ : A tropical ocean recharge mechanism for climate variability. Part II: A unified theory for decadal and ENSO modes. J. Climate, 16, 3599-3616.

Wu, L., Z. Liu, R. Gallimore, R. Jacob, D. Lee, and Y. Zhong, 2003: Pacific decadal variability: The tropical Pacific mode and the North Pacific mode. J. Climate, 16, 1101-1120.

- - - C. Li, and Y. Sun, 2007: Extratropical control of recent tropical Pacific decadal climate variability: A relay teleconnection. Climate Dyn., 28, 99-112.

Zebiak, S. E., and M. A. Cane, 1987: A model El Niño-Southern Oscillation. Mon. Wea. Rev., 115, 2262-2278. 